\title{
Design Procedure and Control of a Hybrid Circuit Breaker with Adaptable Pulse Current Injection
}

\section{Conference Paper}

Author(s):

Jehle, Andreas (i); Biela, Jürgen (i)

Publication date:

2018

Permanent link:

https://doi.org/10.3929/ethz-b-000315787

Rights / license:

In Copyright - Non-Commercial Use Permitted

Originally published in:

https://doi.org/10.23919/IPEC.2018.8507727 


\section{Comparison of Energy Dissipation Concepts for DC Circuit Breakers}

Jehle A., Pally K., Biela J.

Power Electronic Systems Laboratory, ETH Zürich

Physikstrasse 3, 8092 Zürich, Switzerland

“( 2018 EPE Association / IEEE. Personal use of this material is permitted. Permission from EPE Association or IEEE must be obtained for all other uses, in any current or future media, including reprinting/republishing this material for advertising or promotional purposes, creating new collective works, for resale or redistribution to servers or lists, or reuse of any copyrighted component of this work in other works." 


\title{
Comparison of Energy Dissipation Concepts for DC Circuit Breakers
}

\author{
Andreas Jehle, Kessy Pally and Jürgen Biela \\ Laboratory for high power electronic systems, ETH Zürich \\ Email:jehle@hpe.ee.ethz.ch, URL:http://www.hpe.ee.ethz.ch
}

\begin{abstract}
Keywords
$\ll$ HVDC $\gg, \ll$ Multiterminal HVDC $\gg$
\end{abstract}

\begin{abstract}
In DC grids, DC circuit breakers (CB) are used to interrupt currents in case of a fault and to dissipate the remaining energy in the line. Independent of the actually DC CB concept, different energy dissipation concepts can be used, which also influence the performance of the DC CB. In this paper, the energy dissipation with different circuit arrangements, where the energy is dissipated in a single loop, in two loops or in two coupled loops, are discussed and compared. Additionally, the effect of different voltage waveforms across the DC CB and the distribution of the current limiting inductance on the input and the output side of the DC CB are investigated.
\end{abstract}

\section{Introduction}

In recent years, interest in bulk HVDC transmission has significantly increased. One reason is the need for offshore energy transmission from windfarms, which is limited to short distances for AC transmission. Also for transmitting energy from remote power stations and solar parks with low losses, HVDC systems are attractive. Additionally, voltage source converters (VSC) allow a power reversal without a voltage reversal, being a first step to a meshed multi-terminal DC grid with low transmission losses [1].

One of the major remaining problems of HVDC transmission is to turn off lines, especially in case of a fault, where currents rise quickly to high values, because of the relatively low inductances and the high capacitances encountered in HVDC systems. Besides turning off the complete DC grid [2], DC circuit breaker (DC CB) are an attractive solution. There, DC CB must interrupt a (fault) current in the line, must block an increasing transient interruption voltage (TIV) across the DC CB, and must dissipate the remaining energy in the line inductances. To interrupt a current and to block the TIV, DC CB can use mechanical switches (MS), semiconductor switches or a combination of both in so called hybrid circuit breaker (HCB). To dissipate the remaining energy in the line inductances, usually varistors parallel to the DC CB are used. This concept is called single loop energy dissipation (SLED) (Fig.4), because the fault current flows in a single loop.

For most DC CBs, there are several alternative Energy Dissipation Concepts (EDiC) for dissipating the remaining line energy. By dissipating the energy of the inductors in the input and output loop independently (Two loop energy dissipation (TLED) (Fig.5)), the input current can be decreased faster and the total energy to dissipate is smaller. Also, a coupled two loop energy dissipation (CTLED) (Fig.6), which combines the advantages of SLED and TLED, can be used. These alternative EDiCs are generally published as part of a specific DC CB topology and the influence of the used EDiC on the fault current is only compared to the SLED. Only [3] shows the influence of EDiCs on the fault current and the DC CB terminals voltages. However, the comparison is limited to three EDiCs and the variation of the shares of the current limiting inductance on the input and output side of the DC CB.

Therefore, this paper gives a detailed comparison of different EDiCs. First, different parameters of the DC transmission and the DC CBs, which influence the behavior of the EDiCs, are shortly discussed in section 2. Next, seven EDiCs are shown and their working principles are explained in sections 3 - 5. For each EDiC, the influence of the different EDiC parameters and the inductances on the fault current and terminal voltages is shown. Finally, the EDiCs are compared for the transmission line shown in Fig.1 in terms of time to zero current, DC CB terminal voltages, energy to dissipate and component numbers (section 7).

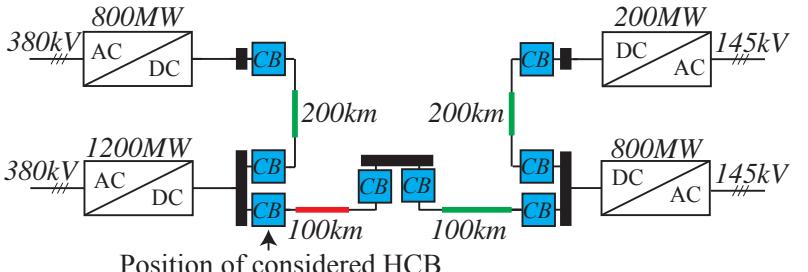

Figure 1: Exemplary block diagram of a 4-terminal symmetric monopolar DC grid [4] including cables (green) and overhead lines (red), which is used for comparing the presented EDiCs. 


\section{Transmission system and DC CB}

\subsection{Transmission system}

In this section, the parameters of the DC line in Fig. 2 are shortly explained.

The voltage sources $V_{D C}$ of a DC line are either other lines, converter stations or both. In case of a fault, the current increase in other lines is limited by the cable inductance. As converter stations usually modular multilevel converters (MMC) are applied, where the IGBTs are simply turned off in case of a fault. Then, the MMC acts as diode rectifier with the arm inductances limiting the current increase. Therefore, the source of the DC line is presented in

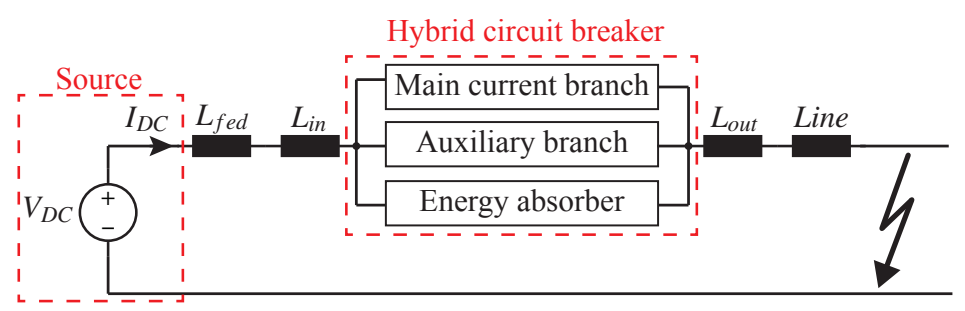

Figure 2: DC CB in a DC transmission system. The DC CB consists of a main current branch, an auxiliary branch and an energy absorber. On both sides are current limiting inductances $L_{i n}$ and $L_{\text {out }}$. The DC source is depicted with an inductance $L_{f e d}$, which represents cable inductances of feeding lines and/or arm inductances of MMC.

the following part as DC source with an inductance $L_{f e d}$ (Fig.2). Despite the inductance $L_{f e d}$, the current increases in most fault cases still to high values during the time required to detect the fault and open the DC CB. Therefore, additional current limiting inductances $L_{i n}$ and $L_{\text {out }}$ are usually added to limit the fault current increase. Additionally, also the inductance of the line $L_{\text {line }}$ from the DC CB to the fault limits the increase of the fault current.

\subsection{DC circuit breaker (DC CB)}

For the fault current interruption, three basic DC CB concepts can be used [5]:

1. Resonant DC CB (Fig.3a) use a resonant circuit parallel to a mechanical circuit breaker (MCB). After opening the MCB under current with an arc, the resonant circuit is excited by the negative resistance of the arc. The increasing oscillating current generates a zero current crossing in the MS and the current commutates to the resonant circuit. The voltage slope across the MCB is limited by the capacitor of the resonant circuit and is determined by the fault current.

2. HCB (Fig.3b) use semiconductors to commutate the current from an ultra-fast disconnector (UFD) quickly to an auxiliary branch. In most $\mathrm{HCBs}$, the voltage increases with a slope determined by a capacitor and by the fault current amplitude after the current commutated from the MS to the auxiliary branch. However, also variants exist, which can control the voltage across the HCB with the number of turned-off semiconductor switches [6, 7] (Fig.3b).

3. Solid state DC CB (Fig.3c) consist only of semiconductors, which can be quickly turned off but generate relatively high on-state losses. Snubbers are used to limit the voltage slope. The voltage across the DC CB can be controlled by the number of turned-off semiconductors.

Basically, all three DC CB concepts can use alternative EDiCs, although varistors parallel to the $\mathrm{HCB}$ and solid state $\mathrm{CB}$ are still required for the overvoltage protection of the semiconductor switches. Important for the EDiC is the current through the DC CB and the voltage across the DC CB. So it is for example possible to increase the voltage across the HCB with a ramp and thereby decrease the maximum fault current and energy to dissipate [8].

Additionally, many DC CB can be realized also as an unidirectional DC CB, which results in a lower number of components. Due to the use of a DC CB at each end of a line, also unidirectional DC CB can be used in DC grids [9]. Therefore, the design of the EDiCs differs if the DC CB is used as unidirec-

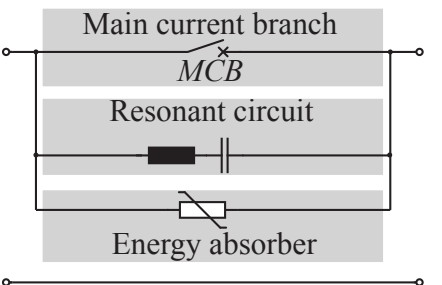

a)

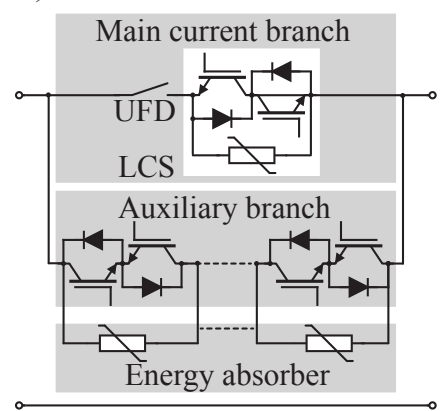

b)

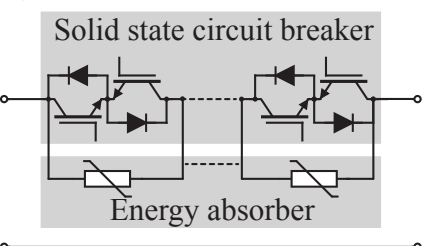

c)

Figure 3: Three different CB concepts with single loop energy dissipation: a) Resonant $\mathrm{CB}$, b) hybrid $\mathrm{CB}$, and c) solid state $\mathrm{CB}$ tional or bidirectional DC CB, which must be considered in a comparison.

\section{Single loop energy dissipation (SLED)}

Most DC CB are published as a two terminal system, where varistors $M O V_{\text {par }}$ parallel to the main current branch are used to dissipate the remaining energy in the line (Fig.4). This results in a coupled input and output current of the DC CB $\left(I_{f, \text { in }}=I_{f, \text { out }}=I_{f}\right)$. After turning off the DC CB, the current is commutated to the varistors $M O V_{\text {par }}$, resulting in a defined maximum TIV across the DC CB $\left(V_{C B}\right)$. If the number of series connected varistors is controlled for example by the number of turned-off IGBTs, the voltage across the DC CB can be controlled. This 
Hybrid circuit breaker with single loop energy dissipation (SLED)

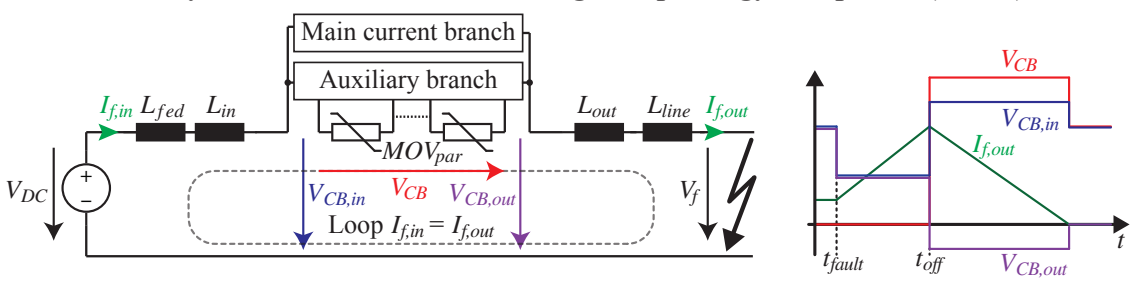

Figure 4: HCB with single loop energy dissipation (SLED): One or more varistors are placed in parallel to the main current branch. The current of the feeding line is therefore equal to the fault current.

allows to keep $V_{C B}$ constant, which results in a faster energy dissipation. The $\frac{d i}{d t}$ of the fault current and the maximum terminal voltage after turn-off are:

$$
\begin{aligned}
& \frac{d I_{f}}{d t}=-\frac{V_{C B}+V_{f}-V_{D C}}{L_{\text {fed }}+L_{\text {fin }}+L_{\text {out }}+L_{\text {line }}} \\
& V_{C B, \text { in }}=V_{D C}+\frac{\left(V_{C B}+V_{f}-V_{D C}\right)\left(L_{f e d}+L_{\text {in }}\right)}{L_{\text {fed }}+L_{\text {fin }}+L_{\text {out }}+L_{\text {line }}}
\end{aligned}
$$

$$
V_{C B, \text { out }}=V_{f}-\frac{\left(V_{C B}+V_{f}-V_{D C}\right)\left(L_{\text {line }}+L_{\text {out }}\right)}{L_{\text {fed }}+L_{\text {fin }}+L_{\text {out }}+L_{\text {line }}}
$$

The SLED has several advantages and disadvantages:

+ The maximum TIV across the DC CB is defined and can be controlled if HCB or solid state DC CB are used.

+ The topology is symmetric and the energy absorbers can therefore be used for decreasing a current in both directions.

- The $d i / d t$ depends on the line inductance and is therefore relatively low, which results in a relatively long time to zero input current and a high energy to dissipate.

- The voltages between the DC CB terminals and ground depend on the inductances and depend therefore on the line length. The terminal voltages could be controlled to some degree by changing the voltage across the DC CB. However, this would require additional measurements and control. To prohibit overvoltages due to oscillations in the grid, additional protection devices are required.

\section{Two loop energy dissipation (TLED)}

Contrary to DC CB with SLED, DC CB with TLED must have at least two connections to ground or to the return conductor. Three different EDiCs for unidirectional current breaking $\left(I_{f, i n}>0\right)$ with TLED are shown in Fig.5. All three use a varistor $M O V_{i n}$ between line and ground on the current feeding side. After the DC CB is turned off, the current of the feeding side $I_{f, \text { in }}$ is commutated to the varistor $M O V_{\text {in }}$ and decreases:

$$
\frac{d I_{f, i n}}{d t}=-\frac{\left(V_{C B, i n}-V_{D C}\right)}{L_{f e d}+L_{i n}}
$$

On the faulty line side, different configurations of varistors, resistors and semiconductors can be used. The EDiC of the HCBs from [10] and [11] uses a series connection of a resistor $R_{\text {out }}$ and a diode $D_{\text {out }}$ (Fig.5a). During normal operation, the diode $D_{\text {out }}$ blocks the system voltage. As soon as the HCB is turned off, the fault current $I_{f, \text { out }}$ is commutated to diode $D_{\text {out }}$ and resistor $R_{\text {out }}$, which dissipates the remaining energy of the faulty line. The current decreases with:

$$
\frac{d I_{f, \text { out }}}{d t}=-\frac{\left(R I_{f, \text { out }}+V_{f}\right)}{L_{\text {out }}+L_{\text {line }}}
$$

With a TLED the maximum voltage across the $\mathrm{HCB}$ is:

$$
V_{C B, \max }=V_{C B, \text { in, } \max }+R I_{f, \text { out }, \max }
$$

Therefore, a faster energy dissipation on the feeding line side results in a slower energy dissipation on the faulty line side for an equal maximum voltage $V_{C B, \max }$.

A possibility to decrease the fault current $I_{f, \text { out }}$ faster is using varistor $M O V_{\text {out }}$ [12] as sown in Fig.5b). The system voltage is again blocked by $D_{\text {out }}$ in normal operation and after the HCB turned off, the fault current $I_{f, \text { out }}$ is commutated to diode $D_{\text {out }}$ and varistor $M O V_{\text {out }}$. The fault current decreases with:

$$
\frac{d I_{f, \text { out }}}{d t}=-\frac{\left(-V_{C B, \text { out }}+V_{f}\right)}{L_{\text {out }}+L_{\text {line }}}
$$


Hybrid circuit breaker with two loop energy dissipation (TLED)
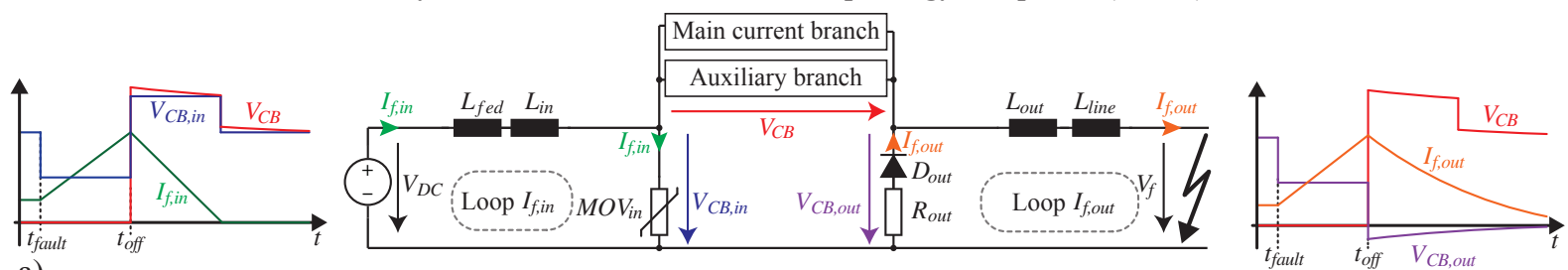

a)
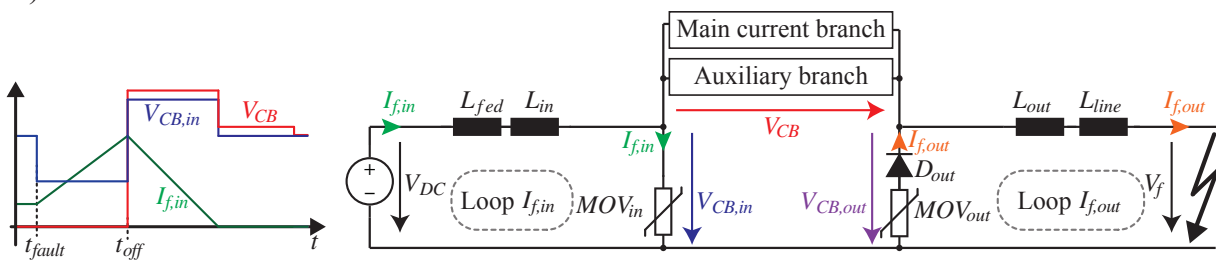

b)
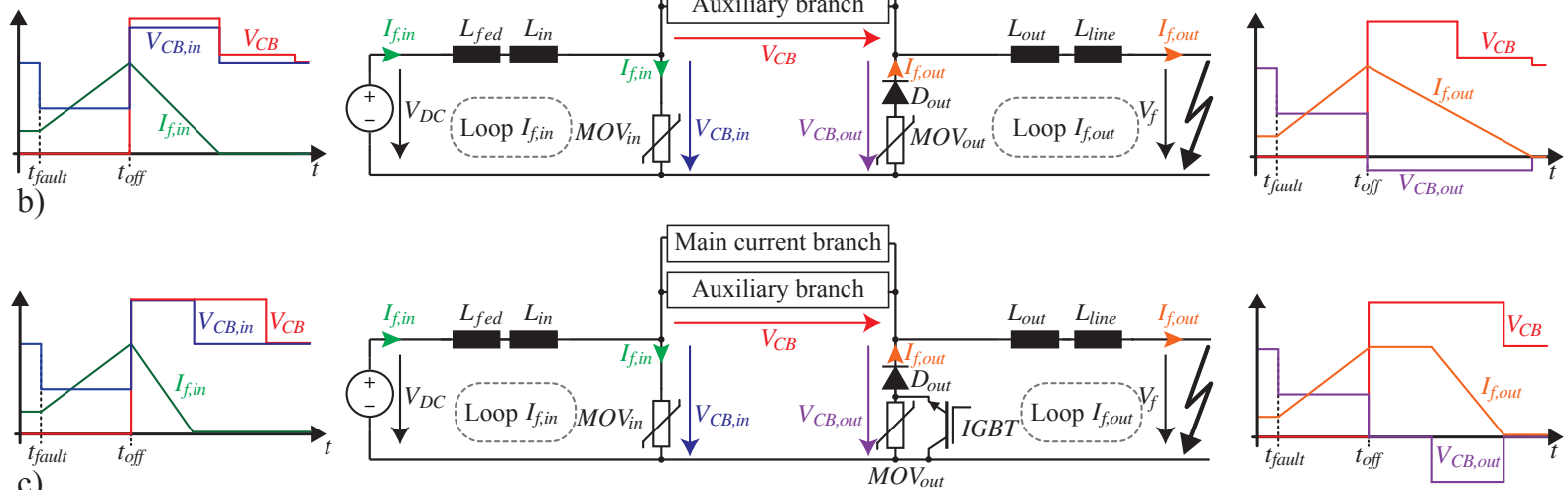

c)

Figure 5: EDiCs for TLED in an unidirectional HCB $\left(I_{f, \text { in }}>0\right)$ : To decrease the current $I_{f, \text { in }}$ of the feeding line, a varistor between line and ground is used. On the faulty line side, diodes are used to block the DC voltage during normal operation. To decrease the current $I_{f, \text { out }}$ a) a resistor b) a varistor or c) a varistor with parallel IGBT is used.

The maximum voltage across the HCB is defined as

$$
V_{C B, \max }=V_{C B, \text { in, } \max }+V_{C B, \text { out }, \max } .
$$

Again, a faster energy dissipation on the feeding line side results in a slower energy dissipation on the faulty line side for an equal maximum voltage $V_{C B, \max }$. However, the fault current $I_{f, \text { out }}$ decreases faster due to the nonlinear varistor $M O V_{\text {out }}$.

Both mentioned topologies with TLED have the maximum terminal voltage $V_{C B \text {,in,max }}$ on the feeding line side and the maximum terminal voltage $V_{C B \text {, out max }}$ for the energy dissipation on the faulty line side directly after the turn-off of the HCB. Therefore, the time to zero of the feeding line current $I_{f, i n}$ depends on the maximum terminal voltage $V_{C B, \text { out,max }}$ for the energy dissipation on the faulty line side. This can be avoided with the topology shown in Fig.5c). This topology uses also a varistor $M O V_{\text {out }}$ and a diode $D_{\text {out }}$. However, an IGBT is used parallel to varistor $M O V_{\text {out }}$, which is turned on during normal operation. After turning the DC CB off, current $I_{f, i n}$ is commutated to varistor $M O V_{i n}$ and generates the terminal voltage $V_{C B, i n}$. The current on the faulty line side is commutated to the IGBT and consequently generates only a small voltage $V_{C B \text {,out }}$. Therefore, the maximum voltage to decrease the feeding line current $I_{f, \text { in }}$ can be equal to the maximum voltage across the $\mathrm{HCB} V_{C B, i n}=V_{C B}$, which results in a fast energy dissipation. As soon as the input current $I_{f, \text { in }}$ decreased that much that $V_{C B, \text { in,max }} \leq V_{C B, \max }-V_{C B, \text { out,max }}$, the IGBT can be turned off and a negative voltage $V_{C B, \text { out }}$ is generated, which decreases the output current (8). In summary, a TLED has several advantages and disadvantages:

+ The feeding line current can be decreased faster.

+ The terminal voltages during the energy dissipation are clearly defined. Additionally, the varistor on the feeding line side limits overvoltages during normal operation and after turn-off.

- The TIV across the HCB cannot be controlled.

- EDiCs with TLED are asymmetric. Therefore, for bidirectional current breaking additional components must be added.

\section{Coupled two loop energy dissipation (CTLED)}

Combinations of SLED and TLED are also possible (Fig.6). As for the SLED, varistors are used in parallel to the DC CB. As for the TLED, different configurations of varistors/resistors and semiconductors can be used for the faulty line side. In case of a fault, the current is commutated to the varistors $M O V_{\text {par }}$ after the DC CB is turned off. This allows to control the voltage $V_{C B}$ across the DC CB by changing the number of series connected varistors $M O V_{\text {par }}$. The fault current decreases as for the SLED if the resulting voltage $V_{C B, \text { out }}$ is positive (3). Otherwise, diodes $D_{\text {out }}$ in Fig.6 start to conduct and the feeding line current $I_{f, \text { in }}$ decreases faster than the current on the faulty line side $I_{f, \text { out }}$. 
In Fig.6a), a diode $D_{\text {out }}$ for blocking the system voltage in normal operation and a resistor $R_{\text {out }}$ for the energy dissipation is used. If diodes $D_{\text {out }}$ start to conduct, the feeding line and the faulty line current decrease with:

$$
\frac{d I_{f, \text { in }}}{d t}=\frac{V_{C B}-V_{D C}-R\left(I_{f, \text { out }}-I_{f, \text { in }}\right)}{L_{f e d}+L_{\text {in }}} \quad \text { (9) } \quad \frac{d I_{f, \text { out }}}{d t}=\frac{R\left(I_{f, \text { out }}-I_{f, \text { in }}\right)+V_{f}}{L_{\text {ou }}+L_{\text {line }}}
$$

In Fig.6b), the current decreases as in the SLED as long as $V_{C B \text {,out }}$ is so high that the varistors $M O V_{\text {out }}$ do not start to conduct (3). When varistors $M O V_{\text {out }}$ start to conduct, the currents decrease independently with:

$$
\frac{d I_{f, \text { in }}}{d t}=\frac{V_{C B}-V_{D C}-V_{C B, \text { out }}}{L_{f e d}+L_{\text {in }}}
$$

$$
\frac{d I_{f, \text { out }}}{d t}=\frac{V_{C B, \text { out }}+V_{f}}{L_{\text {ou }}+L_{\text {line }}}
$$

Similar to the topology in Fig.5c), the voltage $V_{C B, \text { out }}$ in Fig.6c) can be kept at zero by short circuiting the varistor $M O V_{\text {out }}$ [13]. As soon as $V_{C B \text {.out }}$ is not positive (3), the input currents start to decrease:

$$
\frac{d I_{f, i n}}{d t}=-\frac{\left(V_{C B}-V_{D C}\right)}{L_{f e d}+L_{i n}}
$$

The output current $I_{\text {fout }}$ can again be decreased by turning the IGBT off after $I_{f, i n}$ is zero (8).

In general, the CTLED has the following advantages:

+ The maximum TIV across the HCB can be controlled, which allows to some degree to switch between SLED and TLED behavior and therefore between fast energy dissipation and a low blocking voltage, which results in lower distortions for no fault switching.

+ The feeding line current can be decreased faster.

- The terminal voltages are only defined when diode $D_{\text {out }}$ conducts. A complete overvoltage protection requires additional components.

- EDiCs with CTLED are strongly asymmetric. Bidirectional current breaking therefore requires additional components.
Hybrid circuit breaker with coupled two loop energy dissipation (CTLED)

a)

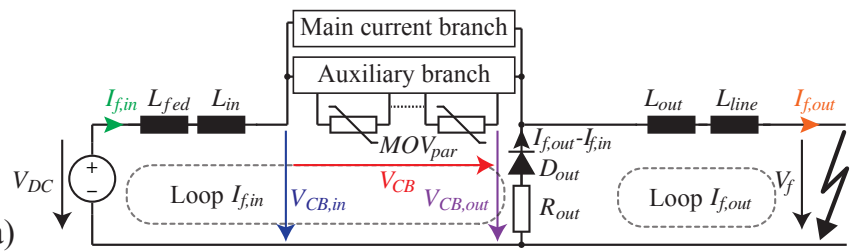

b)

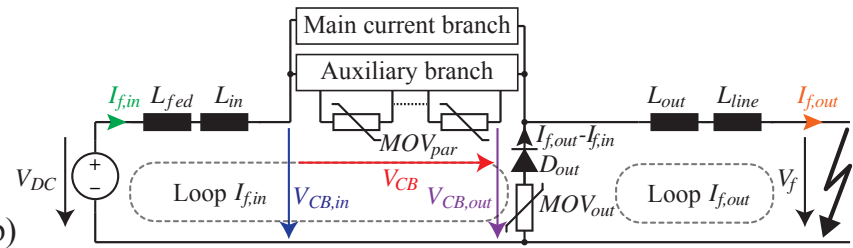

c)

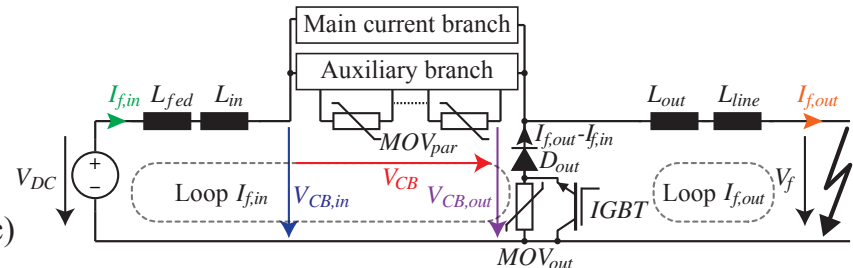

Figure 6: EDiCs for CTLED in an unidirectional HCB $\left(I_{f, i n}>0\right)$ : Depending on the design of the $\mathrm{EDiC}$ and the fault distance, the energy dissipation is similar to the SLED (Fig.4) or to the TLED (Fig.5). The voltage and current waveforms $\left(V_{C B, \text { in }}, V_{C B}, V_{C B, \text { out }}, I_{f, \text { in }}\right.$ and $\left.I_{f, \text { out }}\right)$ are equal to the corresponding waveforms in SLED respectively TLED. Varistors parallel to the main current branch are either used to decrease the current $I_{f, i n}$ in the feeding line or in both lines. For decreasing the current $I_{f, \text { out }}$ in the faulty line during the TLED a) a resistor b) a varistor or c) a varistor with parallel IGBT is used. Diodes are used to block the DC voltage during normal operation.

\section{Setup for the comparison}

In this section, the setup for the simulations of the different EDiCs, whose results are presented in the next section, is shown. The basic setup for the comparison is equal for all investigated EDiCs. A symmetric monopolar four terminal grid with 400kV nominal voltage and MMCs is used for the simulations (DCS2 [4]).

Current limiting reactors are placed in series to each $\mathrm{CB}$ to limit the current increase during a fault. The current limiting inductance value is $L_{\text {lim }}=100 \mathrm{mH}$, which is commonly used as minimum reactor size [14]. The current limiting inductance can be placed at one side of the $\mathrm{CB}$ or divided into two inductors on both sides. In the comparison, the effect of the placement is included by using the current limiting inductor either on the node side, the line side or splitting it in two equal inductors on both sides.

In the simulation of the DC CB, the main current branch and the auxiliary branch of the HCB in Fig.3b) are considered. For the simulation of the EDiCs, the timing of HCB is important since it determines the current amplitudes and the start of the energy dissipation. After an assumed detection time of $2 \mathrm{~ms}$, the current is commutated by the LCS in less than $250 \mu s$ [15]. The UFD is opened next. The maximum opening time of the UFD is $2 m s$ [15]. Two different voltage waveforms can be used during the opening of the UFD:

1. Step: The voltage across the UFD is kept zero during the opening of the UFD [15]. After this 'delay time' of $2 \mathrm{~ms}$, the voltage across the UFD is increased in a single step to the maximum UFD blocking voltage by turning off all IGBTs of the auxiliary branch at the same time. 
Table I: Maximum currents depending on the voltage waveform across the $\mathrm{CB}$ and the distance between $\mathrm{CB}$ and fault.

\begin{tabular}{c|cccc} 
Fault distance & Step & Ramp & Step \& control & Ramp \& Control \\
\hline $0 \mathrm{~km}$ & $11084 \mathrm{~A}$ & $8990 \mathrm{~A}$ & $11084 \mathrm{~A}$ & $8990 \mathrm{~A}$ \\
$50 \mathrm{~km}$ & $8418 \mathrm{~A}$ & $7160 \mathrm{~A}$ & $8418 \mathrm{~A}$ & $7160 \mathrm{~A}$ \\
$100 \mathrm{~km}$ & $7017 \mathrm{~A}$ & $6170 \mathrm{~A}$ & $7017 \mathrm{~A}$ & $6170 \mathrm{~A}$
\end{tabular}

Table II: Energy to dissipate/time to zero (input) current depending on the voltage waveform across the HCB and the distance between HCB and fault for SLED.

\begin{tabular}{c|cccc} 
Fault distance & Step & Ramp & Step \& Control & Ramp \& Control \\
\hline $0 \mathrm{~km}$ & $39.5 \mathrm{MJ} / 17.15 \mathrm{~ms}$ & $28.9 \mathrm{MJ} / 15.14 \mathrm{~ms}$ & $38.0 \mathrm{MJ} / 16.40 \mathrm{~ms}$ & $28.1 \mathrm{MJ} / 14.76 \mathrm{~ms}$ \\
$50 \mathrm{~km}$ & $32.1 \mathrm{MJ} / 18.02 \mathrm{~ms}$ & $24.5 \mathrm{MJ} / 15.62 \mathrm{~ms}$ & $30.5 \mathrm{MJ} / 16.95 \mathrm{~ms}$ & $23.5 \mathrm{MJ} / 15.09 \mathrm{~ms}$ \\
$100 \mathrm{~km}$ & $28.4 \mathrm{MJ} / 19.45 \mathrm{~ms}$ & $22.2 \mathrm{MJ} / 17.10 \mathrm{~ms}$ & $26.8 \mathrm{MJ} / 18.29 \mathrm{~ms}$ & $21.3 \mathrm{MJ} / 16.19 \mathrm{~ms}$
\end{tabular}

2. Ramp: The voltage across the UFD is ramped up during the opening of the UFD. After a short initial acceleration phase, the contact distance increases approximately linear. This allows to increase the voltage proportional to the distance by turning off the individual IGBTs of the auxiliary branch sequentially [8, 16]. The acceleration phase is shorter than $500 \mu s$ [17], which allows to increase the voltage afterwards with $400 \mathrm{kV} / \mathrm{ms}$.

After the blocking voltage of the DC CB increased to the DC voltage of the system, the currents $I_{f, \text { in }}$ and $I_{f, \text { out }}$ start to decrease. Since varistors and/or resistors define the blocking voltage, the blocking voltage decreases as the currents decrease. Therefore, the decrease of the currents slows down while the currents decrease. In this comparison, two additional variants of the above described voltage waveforms are included, which keep the blocking voltage constant for a short time while the currents decrease:

3. Step \& Control: As with waveform 1, the voltage across the UFD is increased in one step to the maximum UFD blocking voltage. As soon as the current decreases, additional IGBTs are turned off to keep the voltage constant. For the comparison, the additional number of IGBTs is chosen to keep the voltage constant until the current is halved.

4. Ramp \& Control: As with waveform 2, the voltage is ramped up to the maximum UFD blocking voltage. As soon as the current decreases, additional IGBTs are turned off to keep the voltage constant. For the comparison, the additional number of IGBTs is chosen to keep the voltage constant until the current is halved.

The first voltage waveform can be used for all EDiCs. The second to fourth voltage waveform can only be used if the voltage across the UFD can be actively controlled, which is only the case for SLED and CTLED. The required passive components for energy dissipation of a CB depends also on its position in the grid and therefore varies for each HCB in the grid [14]. The comparison of the EDiCs are performed for the highlighted CB shown in Fig. 1.

\section{Comparison}

In the following, a comparison of the different EDiCs in terms of time to zero input current, input and output terminal voltage, energy to dissipate and component numbers is shown. The maximum fault current in the $\mathrm{HCB}$ is independent of the used EDiC and depends on the voltage waveform across the HCB and the fault distance (Tab.I). The maximum fault current is reached as soon as the HCB blocks the DC voltage of the system. With a voltage across the HCB before the UFD is completely open the slope of the current decreases, which results in a lower maximum fault current (Fig.7). The additional line inductance of a distant fault decreases also the maximum current.

\subsection{Single loop energy dissipation (SLED)}

In this section, the simulation results of the EDiCs with SLED for different voltage waveforms across the $\mathrm{HCB}$ are presented. The current limiting inductance is equally distributed to both sides of the HCB for the simulations, because the current is decreased in a sin-

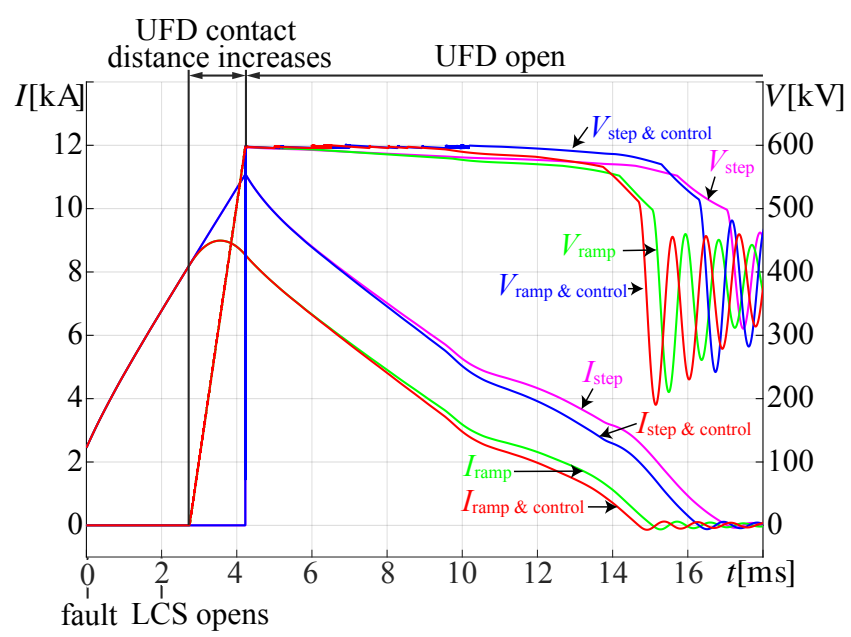

Figure 7: Currents for CBs with SLED depending on the used voltage waveform across the HCB for a fault at $50 \mathrm{~km}$ distance to the HCB. gle loop and the distribution of the current limiting inductance has no influence on the current and the energy to dissipate. The resulting number of varistors are equal for unidirectional and bidirectional current breaking, since EDiCs with SLED are symmetrical. As shown in Fig.7, the different voltage waveforms result in different currents and times to zero current (Tab.II). The maximum energies to dissipate are at a fault close to the HCB $(0 \mathrm{~km})$, while 
Table III: Maximum input/output voltage depending on the voltage waveform across the HCB and the distance between HCB and fault for SLED.

\begin{tabular}{c|cccc} 
Fault distance & Step & Ramp & Step \& Control & Ramp \& Control \\
\hline $0 \mathrm{~km}$ & $563 \mathrm{kV} / 410 \mathrm{kV}$ & $559 \mathrm{kV} / 406 \mathrm{kV}$ & $577 \mathrm{kV} / 406 \mathrm{kV}$ & $568 \mathrm{kV} / 406 \mathrm{kV}$ \\
$50 \mathrm{~km}$ & $906 \mathrm{kV} / 821 \mathrm{kV}$ & $1060 \mathrm{kV} / 808 \mathrm{kV}$ & $908 \mathrm{kV} / 823 \mathrm{kV}$ & $1057 \mathrm{kV} / 824 \mathrm{kV}$ \\
$100 \mathrm{~km}$ & $1450 \mathrm{kV} / 1107 \mathrm{kV}$ & $1070 \mathrm{kV} / 818 \mathrm{kV}$ & $1110 \mathrm{kV} / 818 \mathrm{kV}$ & $1078 \mathrm{kV} / 818 \mathrm{kV}$
\end{tabular}

Table IV: Time to zero input current and energy to dissipate for EDiCs with TLED for 0km distance to the fault (worst case).

\begin{tabular}{c|ccccccc} 
& $V_{R}=10 \mathrm{kV}$ & $V_{R}=50 \mathrm{kV}$ & $V_{M O V}=10 \mathrm{kV}$ & $V_{M O V}=50 \mathrm{kV}$ & $V_{R, M O V}=10 \mathrm{kV}$ & $V_{R, M O V}=50 \mathrm{kV}$ & IGBT \\
\hline$t_{\text {zero,uni }}$ & $13.8 \mathrm{~ms}$ & $15.8 \mathrm{~ms}$ & $13.4 \mathrm{~ms}$ & $14.9 \mathrm{~ms}$ & $13.4 \mathrm{~ms}$ & $14.9 \mathrm{~ms}$ & $13.4 \mathrm{~ms}$ \\
$E_{\text {uni }}$ & $24.4 \mathrm{MJ}$ & $30.5 \mathrm{MJ}$ & $24.5 \mathrm{MJ}$ & $30.4 \mathrm{MJ}$ & $25.1 \mathrm{MJ}$ & $36.9 \mathrm{MJ}$ & $18.5 \mathrm{MJ}$ \\
$t_{\text {zero,bi }}$ & $15.5 \mathrm{~ms}$ & $27.2 \mathrm{~ms}$ & $15.5 \mathrm{~ms}$ & $17.4 \mathrm{~ms}$ & $15.4 \mathrm{~ms}$ & $17.5 \mathrm{~ms}$ & $15.1 \mathrm{~ms}$ \\
$E_{b i}$ & $33.4 \mathrm{MJ}$ & $40.8 \mathrm{MJ}$ & $33.8 \mathrm{MJ}$ & $40.4 \mathrm{MJ}$ & $33.8 \mathrm{MJ}$ & $48.6 \mathrm{MJ}$ & $31.9 \mathrm{MJ}$
\end{tabular}

the time to zero current is maximum for a fault at the other end of the line (here: $100 \mathrm{~km})$. Increasing the voltage during the opening of the UFD leads to a lower current slope and to a decrease of the current before the UFD is completely open. Therefore, the current is already lower for voltage waveforms with a ramped up voltage when the UFD is completely open. This leads finally to a lower energy to dissipate $(36.7 \%$ less) and a lower time to zero current ( $2 \mathrm{~ms}$ shorter). Voltage waveforms with control of the voltage after the opening of the UFD lead to a faster decrease of the current after the opening of the UFD. The constant voltage until the current is halved used in the simulations, corresponds to an increase of the number of IGBTs by less than $2.2 \%$ and leads for SLED to a decrease of the maximum dissipated energy of $4.5 \%$ for the step voltage and $2.8 \%$ for the ramped up voltage.

As already mentioned in section 3 , the input and the output voltages of the HCB depend on the current limiting inductances and the distance to the fault. This leads to relatively high input and output voltages (Tab.III) compared to the nominal system voltage of $400 \mathrm{kV}$.

\subsection{Two loop energy dissipation (TLED)}

For the comparison of the EDiCs with TLED, simulations with the three different EDiCs presented in section 4 have been performed. For the EDiC with resistor on the faulty line side and the EDiC with varistor on the faulty line side, simulations with a maximum negative output voltage of $V_{C B \text {,out }}=-10 \mathrm{kV}$ and $V_{C B \text {,out }}=-50 \mathrm{kV}$ have been performed $\left(V_{R}=10 \mathrm{kV}, V_{R}=50 \mathrm{kV}, V_{M O V}=10 \mathrm{kV}\right.$ and $\left.V_{M O V}=50 \mathrm{kV}\right)$. Accordingly, the maximum input voltage $V_{C B, \text { in }}$ is $590 \mathrm{kV}$ respectively $550 \mathrm{kV}$ in order to limit the maximum voltage across the HCB to $600 \mathrm{kV}$. For the EDiCs with a varistor with parallel IGBT, the maximum input voltage $V_{C B, i n}$ is $600 \mathrm{kV}$. To keep the maximum HCB voltage, the IGBT is turned off so late that the input current and the input voltage already decreased.

Both EDiCs with varistor on the faulty line side use additionally part of $M O V_{\text {in }}$ as $M O V_{\text {out }}$ for bidirectional current breaking. This is also possible for the bidirectional EDiC with resistor by using a series connection of a MOV and a resistor for dissipating the energy on the feeding line side $\left(V_{R, M O V}=10 \mathrm{kV}\right.$ and $\left.V_{R, M O V}=50 \mathrm{kV}\right)$. However, this results in higher energies to dissipate due to the faster decreasing input voltage.

A free parameter of unidirectional EDiCs is the distribution of the current limiting inductance on the feeding and the faulty line side. Generally, all EDiCs with TLED have the lowest energy to dissipate if the current limiting inductance is completely on the faulty line side. As exemplary shown in Fig.8, in this case the current on the feeding line side decreases faster and the energy to dissipate on the feeding line side and the overall energy to dissipate are lower. For bidirectional EDiCs, only an equal distribution should be used as long as the current breaking capability for both sides should be equal.

The performances of the different EDiCs with TLED are depicted in Tab.IV. The lowest energies to dissipate and lowest times to zero current are obtained by deenergizing a small current limiting inductance on the feeding side as fast as possible with a high input voltage. Therefore, unidirectional EDiCs with TLED and high

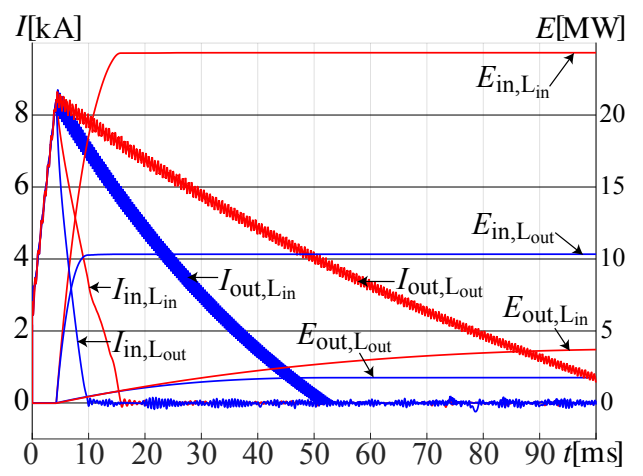

Figure 8: Input and output current of $\mathrm{HCB}$ with SLED for placement of the current limiting inductance either on the input or the output side.

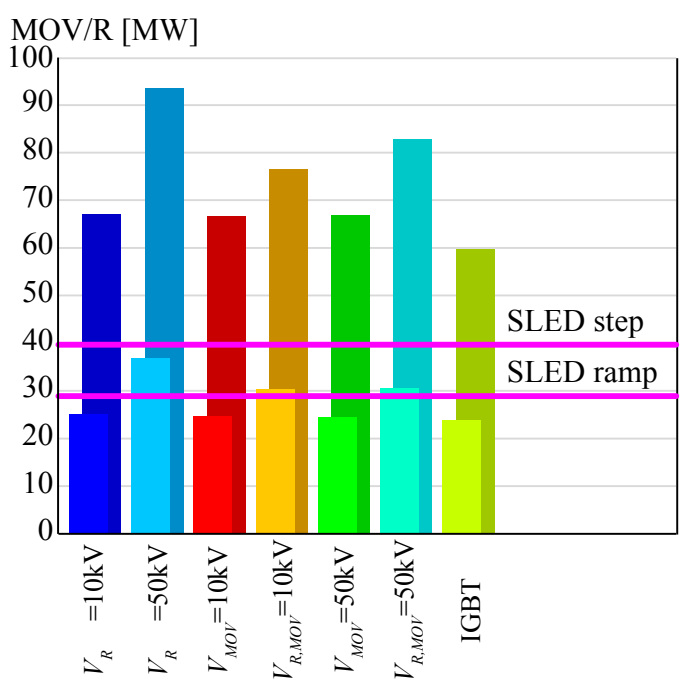

Figure 9: Total installed energy dissipation capability of EDiCs with TLED in comparison to EDiCs with SLED (unidirectional/bidirectional). input voltage can decrease the energy to dissipate and the time to zero input current compared to EDiCs with SLED. EDiCs for bidirectional current breaking have due to the equal distribution of the current limiting inductance higher energies to dissipate and times to zero input current than unidirectional EDiCs with TLED. In contrast to the energy 
Table V: Additional installed semiconductor power and voltages for unidirectional EDiCs for TLED.

\begin{tabular}{c|ccccccc} 
& $V_{R}=10 \mathrm{kV}$ & $V_{R}=50 \mathrm{kV}$ & $V_{M O V}=10 \mathrm{kV}$ & $V_{M O V}=50 \mathrm{kV}$ & $V_{R, M O V}=10 \mathrm{kV}$ & $V_{R, M O V}=50 \mathrm{kV}$ & IGBT \\
\hline$P_{\text {diode }}$ & $6.55 \mathrm{GW}$ & $6.13 \mathrm{GW}$ & $6.56 \mathrm{GW}$ & $6.11 \mathrm{GW}$ & $6.57 \mathrm{GW}$ & $6.08 \mathrm{GW}$ & $6.67 \mathrm{GW}$ \\
$V_{\text {diode, } \max }$ & $591.2 \mathrm{kV}$ & $553 \mathrm{kV}$ & $591.7 \mathrm{kV}$ & $550.9 \mathrm{kV}$ & $592.9 \mathrm{kV}$ & $548.8 \mathrm{kV}$ & $601.8 \mathrm{kV}$ \\
$P_{I G B T}$ & $0 \mathrm{GW}$ & $0 \mathrm{GW}$ & $0 \mathrm{GW}$ & $0 \mathrm{GW}$ & $0 \mathrm{GW}$ & $0 \mathrm{GW}$ & $2.06 \mathrm{GW}$ \\
$V_{I G B T}$ & $0 \mathrm{kV}$ & $0 \mathrm{kV}$ & $0 \mathrm{kV}$ & $0 \mathrm{kV}$ & $0 \mathrm{kV}$ & $0 \mathrm{kV}$ & $185.6 \mathrm{kV}$
\end{tabular}

Table VI: Energy to dissipate for EDiCs with CTLED for 0km distance to the fault (worst case).

\begin{tabular}{c|cccc|cccc} 
& \multicolumn{4}{|c|}{ Unidirectional current breaking HCB } & \multicolumn{4}{c}{ Bidirectional current breaking HCB } \\
& Step & Ramp & Step \& Control & Ramp \& Control & Step & Ramp & Step \& Control Ramp \& Control \\
\hline$V_{R}=10 \mathrm{kV}$ & $23.6 \mathrm{MJ}$ & $17.9 \mathrm{MJ}$ & $22.3 \mathrm{MJ}$ & $17.5 \mathrm{MJ}$ & $32.3 \mathrm{MJ}$ & $23.9 \mathrm{MJ}$ & $31.4 \mathrm{MJ}$ & $23 \mathrm{MJ}$ \\
$V_{R}=50 \mathrm{kV}$ & $27.1 \mathrm{MJ}$ & $20.1 \mathrm{MJ}$ & $25.8 \mathrm{MJ}$ & $19.3 \mathrm{MJ}$ & $37.1 \mathrm{MJ}$ & $28.5 \mathrm{MJ}$ & $36.3 \mathrm{MJ}$ & $27.6 \mathrm{MJ}$ \\
$V_{M O V}=10 \mathrm{kV}$ & $24 \mathrm{MJ}$ & $18.2 \mathrm{MJ}$ & $22.7 \mathrm{MJ}$ & $17.7 \mathrm{MJ}$ & $33.2 \mathrm{MJ}$ & $24.5 \mathrm{MJ}$ & $32 \mathrm{MJ}$ & $23.6 \mathrm{MJ}$ \\
$V_{M O V}=50 \mathrm{kV}$ & $28.8 \mathrm{MJ}$ & $22.1 \mathrm{MJ}$ & $27.6 \mathrm{MJ}$ & $20.7 \mathrm{MJ}$ & $38.7 \mathrm{MJ}$ & $28.6 \mathrm{MJ}$ & $37.6 \mathrm{MJ}$ & $28 \mathrm{MJ}$ \\
$V_{I G B T}=10 \mathrm{kV}$ & $22.5 \mathrm{MJ}$ & $17.6 \mathrm{MJ}$ & $21.6 \mathrm{MJ}$ & $17.2 \mathrm{MJ}$ & $31.6 \mathrm{MJ}$ & $23 \mathrm{MJ}$ & $30.6 \mathrm{MJ}$ & $22.6 \mathrm{MJ}$ \\
$V_{I G B T}=50 \mathrm{kV}$ & $22.7 \mathrm{MJ}$ & $17.6 \mathrm{MJ}$ & $21.7 \mathrm{MJ}$ & $17.2 \mathrm{MJ}$ & $32 \mathrm{MJ}$ & $23 \mathrm{MJ}$ & $30.5 \mathrm{MJ}$ & $22.6 \mathrm{MJ}$
\end{tabular}

dissipation with SLED, the maximum time to zero input current occurs for faults close to the HCB (0km). This is due to the fact that the time to zero input current depends only on the current limiting inductance on the feeding line side and the maximum current apart from the used EDiC with TLED. A disadvantage of EDiCs with TLED for bidirectional current breaking is that only a part of the varistors is used for each current breaking direction. Therefore, the installed energy dissipation capability as shown in Fig.9 is for all HCB with bidirectional current breaking and TLED higher than for SLED. Only unidirectional EDiCs with TLED and high input voltage can decrease the installed energy dissipation capability compared to EDiCs with SLED. An additional drawback of the TLED are that additional diodes and IGBTs are required as shown in Tab.V for unidirectional EDiCs for TLED.

\subsection{Coupled two loop energy dissipation (CTLED)}

For the comparison of EDiCs with CTLED, the three different EDiCs shown in Fig.6 are used with a maximum negative output voltage of $V_{C B, \text { out }}=-10 \mathrm{kV}$ and $V_{C B, \text { out }}=-50 \mathrm{kV}$. Similar to EDiCs with TLED, the distribution of the current limiting inductance to the current feeding line side and the faulty line side of the HCB can be varied for EDiCs with CTLED used for unidirectional current breaking. Similar to EDiCs with TLED, the complete current limiting inductance placed on the faulty line side leads to the lowest energies to dissipate and time to zero current. Therefore, the cases with equal distribution and complete current limiting inductance on the feeding line are not considered for the unidirectional current breaking. Bidirectional current breaking should again be performed with equal distribution of the current limiting inductance to the feeding line side and the faulty line side. Another free design parameter of EDiCs with CTLED is the voltage waveform across the HCB. Again, all four voltage waveforms are considered.

The performance of EDiCs with CTLED in terms of energy to dissipate and time to zero input current are shown in Tab.VI and Tab.VII. The simulations prove that CTLED can combine successfully the advantages of SLED and TLED to improve the performance of HCBs. Similar to EDiCs with TLED, the input current can be decreased faster than with SLED since only half or no current limiting inductance is

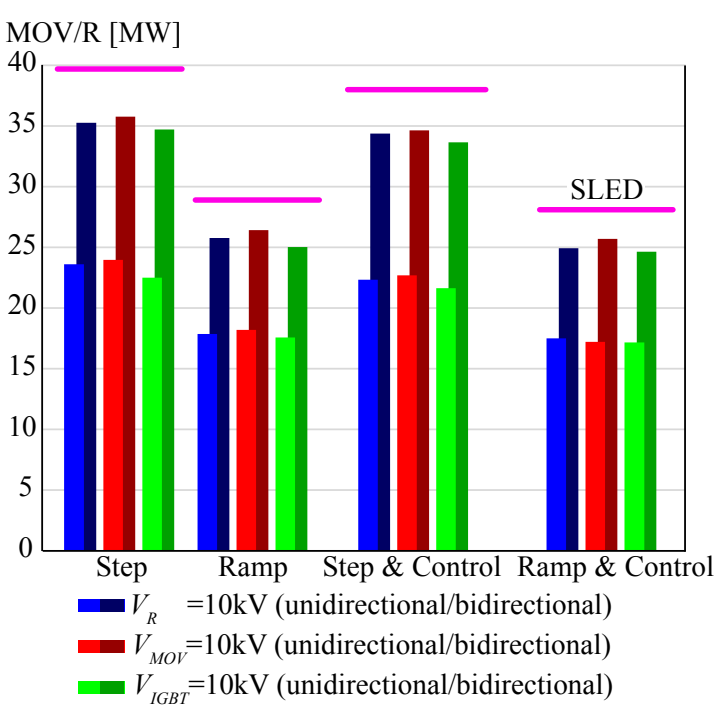

Figure 10: Installed energy dissipation capabilities for EDiCs with CTLED for unidirectional and bidirectional current breaking with a minimum output voltage of $10 \mathrm{kV}$. present in the loop on the feeding side. Additionally, the high input voltage leads again to a faster decreasing input

Table VII: Time to zero input current for EDiCs with CTLED for 0km distance to the fault (worst case).

\begin{tabular}{c|cccc|cccc} 
& \multicolumn{3}{|c|}{ Unidirectional current breaking HCB } & \multicolumn{4}{c}{ Bidirectional current breaking HCB } \\
& Step & Ramp & Step \& Control Ramp \& Control & Step & Ramp & Step \& Control Ramp \& Control \\
\hline$V_{R}=10 \mathrm{kV}$ & $13.3 \mathrm{~ms}$ & $9.7 \mathrm{~ms}$ & $12.8 \mathrm{~ms}$ & $9.4 \mathrm{~ms}$ & $15.2 \mathrm{~ms}$ & $12 \mathrm{~ms}$ & $15 \mathrm{~ms}$ & $13.6 \mathrm{~ms}$ \\
$V_{R}=50 \mathrm{kV}$ & $14.7 \mathrm{~ms}$ & $13.9 \mathrm{~ms}$ & $14.7 \mathrm{~ms}$ & $13.7 \mathrm{~ms}$ & $16.3 \mathrm{~ms}$ & $15.4 \mathrm{~ms}$ & $16 \mathrm{~ms}$ & $14.8 \mathrm{~ms}$ \\
$V_{M O V}=10 \mathrm{kV}$ & $13.7 \mathrm{~ms}$ & $9.8 \mathrm{~ms}$ & $12.8 \mathrm{~ms}$ & $9.4 \mathrm{~ms}$ & $15.4 \mathrm{~ms}$ & $14 \mathrm{~ms}$ & $15.1 \mathrm{~ms}$ & $13.8 \mathrm{~ms}$ \\
$V_{M O V}=50 \mathrm{kV}$ & $14.6 \mathrm{~ms}$ & $14.1 \mathrm{~ms}$ & $14.7 \mathrm{~ms}$ & $13.7 \mathrm{~ms}$ & $16.9 \mathrm{~ms}$ & $15 \mathrm{~ms}$ & $16.4 \mathrm{~ms}$ & $13.8 \mathrm{~ms}$ \\
$V_{I G B T}=10 \mathrm{kV}$ & $13 \mathrm{~ms}$ & $9.4 \mathrm{~ms}$ & $10.2 \mathrm{~ms}$ & $9.1 \mathrm{~ms}$ & $15 \mathrm{~ms}$ & $13.6 \mathrm{~ms}$ & $14.8 \mathrm{~ms}$ & $13.3 \mathrm{~ms}$ \\
$V_{I G B T}=50 \mathrm{kV}$ & $14.6 \mathrm{~ms}$ & $9.8 \mathrm{~ms}$ & $10.5 \mathrm{~ms}$ & $9 \mathrm{~ms}$ & $15.1 \mathrm{~ms}$ & $13.7 \mathrm{~ms}$ & $14.8 \mathrm{~ms}$ & $13.7 \mathrm{~ms}$
\end{tabular}


Table VIII: Maximum terminal voltage of CTLED for bidirectional current breaking and maximum input/output voltages for unidirectional current breaking.

\begin{tabular}{|c|c|c|c|c|c|c|}
\hline \multirow{2}{*}{$\begin{array}{l}\text { Fault } \\
\text { distance }\end{array}$} & \multicolumn{3}{|c|}{ Bidirectional current breaking $\mathrm{HCB}$} & \multicolumn{3}{|c|}{ Unidirectional current breaking HCB } \\
\hline & Ramp & Step \& Control & Ramp \& Control & Ramp & Step \& Control & Ramp \& Control \\
\hline $0 \mathrm{~km}$ & $773 \mathrm{kV} 601 \mathrm{kV}$ & $775 \mathrm{kV}$ & $601 \mathrm{kV}$ & $835 \mathrm{kV} / 434 \mathrm{kV} 598 \mathrm{kV} / 436 \mathrm{kV}$ & $848 \mathrm{kV} / 441 \mathrm{kV}$ & $601 \mathrm{kV} / 436 \mathrm{kV}$ \\
\hline $50 \mathrm{~km}$ & $1 \mathrm{kV} 596 \mathrm{kV}$ & 808 & $602 \mathrm{kV}$ & $\mathrm{kV} 599 \mathrm{kV} / 5$ & $1002 \mathrm{kV} / 599 \mathrm{kV}$ & $99 \mathrm{kV}$ \\
\hline $100 \mathrm{~km}$ & $893 \mathrm{kV} 593 \mathrm{kV}$ & $893 \mathrm{kV}$ & $601 \mathrm{kV}$ & $974 \mathrm{kV} / 639 \mathrm{kV} 637 \mathrm{kV} / 637 \mathrm{kV}$ & $985 \mathrm{kV} / 639 \mathrm{kV}$ & $637 \mathrm{kV} / 637 \mathrm{kV}$ \\
\hline
\end{tabular}

Table IX: Additional installed powers of IGBTs for EDiCs with varistor with parallel IGBT (10kV/50kV output voltage) and diodes for EDiCs with CTLED.

\begin{tabular}{|c|c|c|c|c|c|c|c|c|}
\hline & \multicolumn{4}{|c|}{ Bidirectional current breaking HCB } & \multicolumn{4}{|c|}{ Unidirectional current breaking HCB } \\
\hline & Step & Ramp & Step \& Contr & Ramp \& Control & Step & Ramp & Step \& Contr & Ramp \& Control \\
\hline Diodes & $19.8 \mathrm{GW}$ & $10.81 \mathrm{GW}$ & $19.8 \mathrm{GW}$ & $10.81 \mathrm{GW}$ & $7.08 \mathrm{GW}$ & $5.73 \mathrm{GW}$ & $7.08 \mathrm{GW}$ & $5.73 \mathrm{GW}$ \\
\hline IGBTs $(10 \mathrm{kV})$ & $0.22 \mathrm{GW}$ & $0.18 \mathrm{GW}$ & $0.22 \mathrm{GW}$ & $0.18 \mathrm{GW}$ & $0.11 \mathrm{GW}$ & $0.09 \mathrm{GW}$ & $0.11 \mathrm{GW}$ & $0.09 \mathrm{GW}$ \\
\hline IGBTs $(50 \mathrm{kV})$ & $1.11 \mathrm{GW}$ & $0.45 \mathrm{GW}$ & $1.11 \mathrm{GW}$ & $0.45 \mathrm{GW}$ & $0.55 \mathrm{GW}$ & $0.22 \mathrm{GW}$ & $0.55 \mathrm{GW}$ & $0.22 \mathrm{GW}$ \\
\hline
\end{tabular}

current due to the low output voltages. Therefore, lower minimum output voltages ensure again a lower energy to dissipate and a lower time to zero current. Similar to EDiCs with SLED, the voltage across the UFD can be controlled and increased earlier, which also leads to a faster energy dissipation.

In terms of the installed energy dissipation capability, EDiCs with CTLED benefit from the lower energy to dissipate and in case of bidirectional current breaking from the usage of varistors parallel to the UFD for current breaking in both directions (Fig.10). While EDiCs with CTLED combine the advantages of SLED and TLED in terms of performance and a low installed energy dissipation capability, EDiCs with CTLED combine also the disadvantages in terms of high terminal voltages and high numbers of required semiconductors. One of the main problems is that the terminal voltages are only limited by the HCB during the interruption as soon as the diode conducts. When and if the diode starts to conduct depends on several parameters as the voltage across the HCB and the distribution of the current limiting inductances and the line inductances, respectively the distance to the fault (Tab.VIII). Additionally, the diode does not directly start to conduct as soon as the HCB voltage has been increased. Therefore, a fast stepwise increase of the voltage across the UFD leads to a higher input voltage than a slow ramped up voltage across the UFD, which enables the current to commutate to the diode before the maximum voltage across the UFD is reached. Because of the high terminal voltages, also the number of required diodes is high (Tab.IX) and require an additional overvoltage protection.

\section{Conclusion}

In this paper, energy dissipation concepts for DC CB are presented and compared. The paper discusses the advantages and disadvantages of dissipating the energy with a SLED, a TLED and a CTLED. Additionally, the effects of different voltage waveforms across the UFD and different distributions of the current limiting inductance on the current feeding and the faulty line side of unidirectional DC CB are discussed. In the second part of the paper, simulation results are used to compare the different concepts in terms of required components and performance (Tab.X).

SLED can be used without additional semiconductors and the installed energy dissipation capability is the same for unidirectional and bidirectional current breaking. In addition, the ramped up voltage across the UFD results in a faster energy dissipation than with a single voltage step. For bidirectional current breaking, this allows a $12 \%$ lower energy to dissipate than for TLED and a 53\% lower installed energy dissipation capability than for TLED, although the time to zero current is $1.1 \mathrm{~ms}$ longer for the considered system (Fig.1). However, for unidirectional current breaking, placing the complete current limiting inductance on the output side results for TLED in a lower energy to dissipate $(-22 \%)$ and a $2.8 \mathrm{~ms}$ lower time to zero input current. In addition, the installed energy dissipation capability can be decreased by $15 \%$ and the terminal voltages are limited. An even better performance can be achieved with CTLED by using a ramped up voltage across the UFD and placing the complete current limiting inductance on the output side. For unidirectional current breaking, the time to zero input current decreases by $7.2 \mathrm{~ms}$ compared to SLED, respectively by $4.4 \mathrm{~ms}$ compared to TLED. This is also true for bidirectional current breaking with $2.2 \mathrm{~ms}$ shorter time to zero current compared to SLED and $1.5 \mathrm{~ms}$ shorter time to zero current compared to TLED. Also the energy to dissipate and the installed energy dissipation capability are below SLED and TLED. Therefore, the use of a CTLED is clearly advantageous for unidirectional and bidirectional current breaking alike and should be considered for future DC CB.

Table X: Comparison of SLED, TLED and CTLED

\begin{tabular}{c|ccc} 
& SLED & TLED & CTLED \\
\hline Time to zero input current & high & medium & low \\
Maximum dissipated energy & high & medium & low \\
Terminal voltages limited & no & yes & additional \\
Installed energy dissipation capability & medium & high & low \\
Additional required semiconductors & non & yes & yes
\end{tabular}




\begin{tabular}{lcll} 
& \multicolumn{3}{c}{ List of abbreviations } \\
CB & circuit breaker & VSC & voltage source converter \\
HVDCs & high voltage dc & TIV & transient interruption voltage \\
MS & mechanical switch & HCB & hybrid circuit breaker \\
SLED & single loop energy dissipation & EDiC & energy dissipation concepts \\
TLED & two loop energy dissipation & CTLED & coupled two loop energy dissipation \\
MMC & modular multilevel converter & MCB & mechanical circuit breaker \\
UFD & ultra-fast disconnector & MMC & modular multilevel converter \\
MOV & metal oxide varistor & IGBT & insulated-gate bipolar transistor \\
LCS & load commutating switch & &
\end{tabular}

\section{Acknowledgment}

This project is carried out in the frame of the Swiss Centre for Competence in Energy Research on the Future Swiss Electrical Infrastructure (SCCER-FURIES) with the financial support of the Swiss Commission for Technology and Innovation (CTI - SCCER program).

\section{References}

[1] C. Franck, "HVDC Circuit Breakers: A Review Identifying Future Research Needs," IEEE Trans. Power Del., vol. 26, no. 2, pp. 998-1007, April 2011.

[2] D. Schmitt, Y. Wang, T. Weyh, and R. Marquardt, "DC-side fault current management in extended multiterminal-HVDC-grids," in 9th Int. Multi-Conf. on Systems, Signals and Devices (SSD), March 2012.

[3] R. Sander and T. Leibfried, "Considerations on energy absorption of HVDC circuit breakers," in 49th Int. Universities Power Engineering Conf., Sept 2014.

[4] Guide for the Development of Models for HVDC Converters in a HVDC Grid. C CIGRE, 2014.

[5] M. Bucher and C. Franck, "Fault current interruption in multiterminal HVDC networks," IEEE Trans. Power Del., no. 99, 2015.

[6] J. Häfner and B. Jacobson, "Proactive hybrid HVDC breakers-A key innovation for reliable HVCD grids," in Symposium on the electric power system of the future-Integrating supergrids and microgrids, Sept 2011.

[7] A. Jehle and J. Biela, "Hybrid circuit breaker for HVDC grids with controllable pulse current shape," in 19th Eur. Conf. on Power Electronics and Appl. (EPE ECCE Europe), Sept 2017.

[8] F. B. Effah, A. J. Watson, C. Ji, E. Amankwah, C. M. Johnson, C. Davidson, and J. Clare, "Hybrid HVDC circuit breaker with self-powered gate drives," IET Power Electronics, vol. 9, no. 2, pp. 228-236, 2016.

[9] A. Jehle, D. Peftitsis, and J. Biela, "Unidirectional hybrid circuit breaker topologies for multi-line nodes in HVDC grids," in 18th Eur. Conf. on Power Electronics and Appl. (EPE ECCE Europe), Sept 2016.

[10] Y. Wang and R. Marquardt, "Operation of Modular Multilevel Converter and DC-Breaker in large Multiterminal-HVDC-Grids," in Conf. for Power Electronics, Intelligent Motion, Renewable Energy and Energy Management (PCIM), May 2013.

[11] _ _ "Performance of a new fast switching DC-breaker for meshed HVDC-grids," in 17th Eur. Conf. on Power Electronics and Appl. (EPE ECCE-Europe), Sept 2015.

[12] R. Sander, M. Suriyah, and T. Leibfried, “A Novel Current-Injection Based Design for HVDC Circuit Breakers," in Conf. for Power Electronics, Intelligent Motion, Renewable Energy and Energy Management (PCIM), May 2015.

[13] X. Jiang and M. M. Bakran, "A new protection scheme for HVDC circuit based on MMC topology with controllable fault current," in 18th Eur. Conf. on Power Electronics and Appl. (EPE ECCE Europe), Sept 2016.

[14] Technical requirements and specifications of state-of-the-art HVDC switching equipment. C CIGRE, 2017.

[15] A. Hassanpoor, J. Häfner, and B. Jacobson, “Technical assessment of load commutation switch in hybrid HVDC breaker," in Int. Power Electronics Conf. (IPEC-Hiroshima - ECCE-ASIA), May 2014.

[16] M. H. Hedayati and D. Jovcic, "Reducing peak current and energy dissipation in hybrid HVDC CBs using disconnector voltage control," IEEE Trans. Power Del., vol. 33, no. 4, pp. 2030-2038, Aug 2018.

[17] P. Skarby and U. Steiger, "An ultra-fast disconnecting switch for a hybrid HVDC breaker - a technical breakthrough," Cigre Symposium, Alberta, Canada, Sep 2013. 